\title{
Mechanistic Links Underlying the Impact of C-Reactive Protein on Muscle Mass in Elderly
}

\author{
Britta Wåhlin-Larsson ${ }^{a}$ Daniel J. Wilkinson ${ }^{b}$ Emelie Strandberga \\ Adrian Hosford-Donovan ${ }^{\mathrm{a}}$ Philip J. Atherton ${ }^{\mathrm{b}}$ Fawzi Kadia \\ aSchool of Health and Medical Sciences, Örebro University, Örebro, Sweden; ${ }^{b} M R C-A R U K$ Centre of \\ Excellence for Musculoskeletal Ageing Research, Division of Medical Sciences and Graduate Entry \\ Medicine, University of Nottingham, Royal Derby Hospital Centre, Derby, UK
}

\section{Key Words}

Ageing - AMPK • Akt/mTOR - Chronic Inflammation - CRP • Myoblast - Protein Synthesis • Skeletal Muscle Cell $\bullet$ Old women

\begin{abstract}
Background/Aims: Mechanisms underlying the relationship between systemic inflammation and age-related decline in muscle mass are poorly defined. The purpose of this work was to investigate the relationship between the systemic inflammatory marker CRP and muscle mass in elderly and to identify mechanisms by which CRP mediates its effects on skeletal muscle, in-vitro. Methods: Muscle mass and serum CRP level were determined in a cohort of 118 older women (67 \pm 1.7 years). Human muscle cells were differentiated into myotubes and were exposed to CRP. The size of myotubes was determined after immunofluorescent staining using troponin. Muscle protein synthesis was assessed using stable isotope tracers and key signalling pathways controlling protein synthesis were determined using western-blotting. Results: We observed an inverse relationship between circulating CRP level and muscle mass $(\beta=-0.646(95 \%$ CI: $-0.888,-0.405) p<0.05)$ and demonstrated a reduction $(p<0.05)$ in the size of human myotubes exposed to CRP for $72 \mathrm{~h}$. We next showed that this morphological change was accompanied by a CRP-mediated reduction $(p<0.05)$ in muscle protein fractional synthetic rate of human myotubes exposed to CRP for $24 \mathrm{~h}$. We also identified a CRPmediated increased phosphorylation $(p<0.05)$ of regulators of cellular energy stress including AMPK and downstream targets, raptor and ACC- $\beta$, together with decreased phosphorylation of Akt and rpS6, which are important factors controlling protein synthesis. Conclusion: This work established for the first time mechanistic links by which chronic elevation of CRP can contribute to age-related decline in muscle function.
\end{abstract}




\section{Introduction}

A major healthcare concern related to ageing is sarcopenia, which is characterised by a progressive decline in muscle mass, and function, increased risk of falls, metabolic diseases, loss of independence and increased mortality [1]. Given the incipient nature of sarcopenia (i.e. 1-2\% loss per year $>50$ y) [2], underlying mechanisms must act slowly inducing sustained but minor alterations, which over decades, lead to clinically relevant consequences.

The balance between muscle protein synthesis (MPS) and muscle protein breakdown (MPB) is the key factor controlling muscle mass i.e. muscle mass is stable when MPS=MPB, whereas muscle loss occurs when MPB>MPS. Altered sensitivity to habitual anabolic stimuli has been put forward as a putative mechanism behind the slow and progressive loss of muscle mass during ageing. Blunted response to anabolic stimuli such as nutrition [3] and physical exercise [4] in muscles of elderly individuals has been demonstrated; this so called "anabolic resistance" is a putative driver of sarcopenia. Noteworthy, muscle protein synthetic response was not substantially impaired in a study performed in healthy elderly men [5] and a retrospective analysis of MPS data in old and young subjects showed that maximal stimulation of postprandial rates of MPS in old requires a greater relative protein intake than in young [6]. While the aetiology of anabolic resistance is poorly understood, impaired regulation of anabolic signalling pathways (e.g. mechanistic target of rapamycin, mTOR) regulating MPS are thought to be central [7].

One putative mechanism behind age-related reductions in muscle mass is chronic inflammation [8]. Several observational studies reported associations between chronic inflammation and the loss of strength and muscle mass in elderly [9-14]. Nonetheless, the specific inflammatory drivers of muscle atrophy and dysfunction remain poorly defined. In this respect, circulating acute phase C-reactive protein (CRP) is an established "biomarker" of systemic inflammation and is recognized as an important factor underlying several agerelated deleterious changes [15-19]. Thus, the possibility remains CRP itself could be a driver of muscle catabolism. Statistical relationships between MPS and inflammation have been addressed in three reports, albeit with conflicting results; i.e. muscle protein metabolism being impaired in two $[20,21]$ but not a third [22]. The potential mechanisms by which CRP might negatively affect muscle mass have not been addressed.

Clearly, identification of links between declines in muscle mass, alterations in MPS and inflammatory factors driving muscle catabolism deserves further attention since this might produce targets for therapeutic intervention. To this end, the aim of the present work was two-fold. Firstly, we met out to forge statistical relationships between circulating serum CRP levels and muscle mass in a cohort of 118 older women (age: $67 \pm 2$ years) and, secondly, to identify the mechanisms by which CRP mediates its effects on skeletal muscle, in vitro.

\section{Materials and Methods}

\section{Subjects}

One hundred and eighteen elderly women (age: $67 \pm 2$ years) were included in the study. They were non-smokers, had no disability regarding mobility and were free of metabolic and inflammatory diseases, diagnosed coronary heart disease or diabetes mellitus. None of the subjects had a serum CRP higher than $6 \mathrm{mg} / \mathrm{L}$. Informed consent was obtained from all subjects and the study was conducted in accordance with principles set out in the Declaration of Helsinki and approved by the regional ethical review board of Uppsala.

Height and body weight were assessed using standardized procedures. Muscle mass was assessed between 7.00 and $9.00 \mathrm{am}$, after an overnight fast using bioelectrical impedance analysis (BIA) (TANITA BC-420MA, Tanita Corporation, Japan). Skeletal muscle mass was calculated using the equation of Janssen et al. (2002) [2]: Skeletal muscle mass $(\mathrm{kg})=\left[\left(\right.\right.$ height $^{2} /$ BIA-resistance $x$ 0.401) $+($ gender $x 3.825)+($ age $\mathrm{x}-0.071)]+5.102$ where, height is in cm; BIA-resistance is in ohms; gender $=0$ for women; age is in years. Skeletal muscle mass index (SMI \%) was calculated as follows: skeletal muscle mass / body mass x 100. 


\section{Cellular Physiology Cell Physiol Biochem 2017;44:267-278 \begin{tabular}{l|l|l} 
and BOI:10.1159/000484679 & $\begin{array}{l}\text { (c) 2017 The Author(s). Published by S. Karger AG, Basel } \\
\text { www.karger.com/cpb }\end{array}$
\end{tabular} \\ Wåhlin-Larsson et al.: CRP, Protein Synthesis \& Muscle Mass in Elderly}

According to Janssen et al. [2], low muscle mass is defined as an SMI below 28\%. Maximal isometric knee extension was measured in subjects seated on an adjustable chair with a $90^{\circ} \mathrm{C}$ angle of hip and knee joints as previously described [23]. Maximal isometric knee extension was expressed relative to body weight (N/kg).

Blood samples were obtained between 7.00 and $9.00 \mathrm{am}$, after an overnight fast. Participants were asked to avoid smoking and alcohol and not to engage in any strenuous physical activity $24 \mathrm{~h}$ before the blood sample. Blood was collected by venepuncture from an antecubital vein, centrifuged at $4000 \mathrm{rpm}$ for 10 minutes, aliquoted and stored at $-80^{\circ} \mathrm{C}$. Levels of triglycerides and LDL and HDL-cholesterol were determined on a Vitros-5.1-analyser platform using chemistry kits from Ortho-Clinical Diagnostics, Johnson \& Johnson. Level of plasma glucose was determined with the Roche Reflotron Plus ${ }^{\circledR}$ system. CRP level was measured using a high-sensitivity C-reactive protein (Hs-CRP) kit by a fully automated immunoturbidimetric assay (Advia 1800, Chemistry System, Siemens, Germany).

\section{Isolation and purification of myoblasts from human biopsies}

Muscle biopsies obtained from vastus lateralis of 7 elderly women (age $66.9 \pm 1.2$ years) were scissorminced and explants were trapped inside a thin layer of $6 \mathrm{mg} / \mathrm{ml}$ Matrigel (BD Matrigel Matrix from BD Biosciences) in $35 \mathrm{~mm}$ collagen-coated Petri dishes with growth media (Dulbecco's Modified Eagle Medium, DMEM, Sigma) supplemented with 20\% fetal bovine serum (Hyclone Perbio), 2\% Ultroser G (Pall, France), $10 \mathrm{mM}$ Hepes (H0887, Sigma) and $50 \mu \mathrm{g} / \mathrm{ml}$ Gentamicin (G1397, Sigma). After 6 to 8 days, cells migrated out of the explants. Migrating cells were enzymatically harvested using dispase (BD Biosciences) and subcultured in growth medium. Harvested cells were purified by immunomagnetic cell sorting as previously described [19].

\section{Effects of CRP on the size of myotubes}

Myoblasts obtained from 7 elderly subjects were seeded at $1 \times 10^{6}$ cells/dish onto $35 \mathrm{~mm}$ collagencoated dishes and cultured in growth medium. At confluence, cells were differentiated into myotubes in differentiation medium containing DMED. Differentiated myotubes were kept in differentiation medium without (Control) and with CRP $(50 \mu \mathrm{g} / \mathrm{ml}, \mathrm{C} 1617$ Sigma) for $72 \mathrm{~h}$. Cells were then immunostained for $2 \mathrm{~h}$ at room temperature using the primary antibodies against myogenin (mouse monoclonal Sigma 1:100) and troponin (rabbit polyclonal Santa Cruz, 1:100). Secondary antibodies Alexa fluor 568 (goat anti-mouse) and Alexa fluor 488 (goat anti-rabbit) were used. Nuclei are stained blue with DAPI. Myotube diameter was quantified using Image s software on 6 randomly chosen fields yielding approximately 140 myotubes per cell culture. The average diameter of one myotube was calculated as the mean of 5 measurements performed along the length of that myotube.

\section{Effect of CRP on myotube mixed protein synthesis (MPS)}

Differentiated myotubes were kept in differentiation medium without (Control, CON) and with CRP $(50 \mu \mathrm{g} / \mathrm{ml}, \mathrm{C} 1617 \mathrm{Sigma})$ for $24 \mathrm{~h}$. All samples were measured in at least duplicates. Chronic measures of protein synthesis rates were performed using the stable isotope tracer deuterium oxide $\left(\mathrm{D}_{2} \mathrm{O}\right) .5 \% \mathrm{D}_{2} \mathrm{O}$ was added in both control and CRP-treated cell cultures. Following incubations, $1 \mathrm{ml}$ of media was sampled from each well and cells were washed twice with ice cold PBS and harvested into 200ul of ice cold homogenisation buffer (50 mM Tris-HCl (pH 7.4), 50 mM NaF, 10 mM $\beta$-Glycerophosphate disodium salt, 1 mM EDTA, 1 mM EGTA, 1 mM activated $\mathrm{Na}_{3} \mathrm{VO}_{4}$ ) (all Sigma-Aldrich, Poole, UK) and a complete protease inhibitor cocktail tablet (Roche, West Sussex, UK). Following homogenisation, samples were centrifuged at $10000 \mathrm{~g}$ for $10 \mathrm{mins}$ at $4^{\circ} \mathrm{C}$ to separate the sarcoplasmic proteins and $50 \mathrm{ul}$ of the supernatant was transferred to a fresh eppendorf and frozen for western blotting analyses. To the remaining supernatant and pellet an equal volume of $1 \mathrm{M}$ PCA was added to precipitate any remaining sarcoplasmic proteins. The sample was incubated on ice for 30 mins and centrifuged at $10000 \mathrm{~g}$ for 10 mins at $4^{\circ} \mathrm{C}$. The PCA supernatant (containing free amino acids) was transferred to a fresh eppendorf and frozen, whilst the pellet was washed sequentially with PCA: $70 \%$ ethanol: $70 \%$ ethanol to remove any remaining free amino acids. The mixed muscle pellet was then hydrolysed overnight at $110^{\circ} \mathrm{C}$ in $1 \mathrm{ml}$ of $0.1 \mathrm{M} \mathrm{HCl}$ and $1 \mathrm{ml}{ }^{+} \mathrm{H}$ dowex resin. Hydrolysed AA were then eluted from the dowex resin the following day into $2 \mathrm{M} \mathrm{NH}_{4} \mathrm{OH}$ and evaporated to dryness. Deuterium labelling of protein bound alanine was then determined using GC-MS/MS (Trace 1310-TSQ 8000, Thermo Scientific, Hemel Hempstead, UK) following conversion to its n-methoxycarbonyl methyl ester derivative and single reaction monitoring (SRM). The media sampled from each well was measured for D20 enrichment using a 


\section{$\begin{array}{ll}\text { Cellular Physiology } & \text { Cell Physiol Biochem 2017;44:267-278 } \\ \text { DOI: 101159/000484679 } 0 \text { 2017 The Author(s). Published by S. Karger AG, Basel }\end{array}$

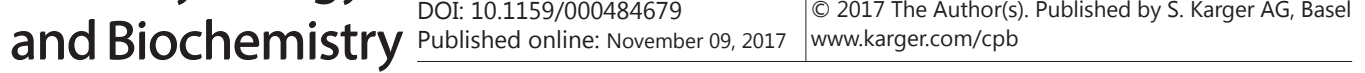

modification of the acetone exchange method [24]. Briefly, $2 \mathrm{ul}$ of $10 \mathrm{~N} \mathrm{NaOH}$ was added to $100 \mathrm{ul}$ of media, following a 15 s vortex mix $1 \mathrm{ul}$ of acetone was added. This was incubated for $24 \mathrm{~h}$ to allow full hydrogen/ deuterium exchange. The acetone was then extracted into 200ul of n-heptane, the n-heptane layer was transferred to an autosampler vial and 0.5ul injected into the GC-MS (Trace 1300-ISQ, Thermo Scientific, Hemel Hempstead, UK). D20 enrichment was determined via SIM of m/z 58 and 59 with reference to a standard curve of known D20 enrichments. FSR was calculated using the following equation:

$$
\operatorname{FSR}(\% / \mathrm{h})=\left[\left(\mathrm{MPE}_{\mathrm{Ala}}\right)\right] /\left[3.7 \times\left(\mathrm{MPE}_{\mathrm{MW}}\right) \times \mathrm{t}\right)[25] .
$$

Where $\mathrm{MPE}_{\mathrm{Ala}}$ represents protein bound alanine enrichment, $\mathrm{MPE}_{\mathrm{MW}}$ represents media water enrichment and t represents time in hours.

\section{Western Blot analysis}

The sarcoplasmic fraction was used for immunoblot analysis. Sarcoplasmic protein concentrations were determined using a NanoDrop Lite spectrophotometer (Thermo Scientific, hemel Hempstead, UK) and adjusted to $0.3 \mu \mathrm{g} \cdot \mu^{-1}$ in $3 \times$ laemmli buffer. Each sample was loaded onto pre-cast $12 \%$ Bis-Tris Criterion XT gels (BioRad, Hemel Hempstead, UK) at $4.5 \mu \mathrm{g}$ per lane and separated electrophoretically at $200 \mathrm{~V}$ for 1 $\mathrm{h}$. Proteins were then wet-transferred at $100 \mathrm{~V}$ for $1 \mathrm{~h}$ onto polyvinylidene difluoride (PVDF) membranes $(0.22 \mu \mathrm{m}$ pore size), blocked for 1 hour in $2.5 \%$ skimmed milk in $1 \times$ Tris-buffered saline Tween-20 (TBS-T), and then incubated in primary antibodies (1:2000 dilution in 2.5\% BSA in TBS-T); phospho-serine/ threonine kinase Akt ( $\left.\mathrm{p}-\mathrm{Akt}^{\mathrm{Ser} 473}\right)$, phospho-ribosomal protein S6 (p-RPS6 ${ }^{\text {Ser235/236 }}$ ), phospho-AMP-activated protein kinase (p-AMPKo ${ }^{\text {Thr172 }}$ ), phospho-raptor (p-Raptor ${ }^{\text {Ser792 }}$ ), phospho-acetyl-CoA carboxylase (p-ACC$\beta^{\text {Ser79) }}$ (New England Biolabs, Hertfordshire, UK), rocking overnight at $4^{\circ} \mathrm{C}$. The next day membranes were subsequently washed $3 \times 5$ min in TBS-T, incubated in HRP-conjugated secondary antibody (New England Biolabs, Hertfordshire, UK; 1:2000 in 2.5\% BSA in TBS-T) at room temperature for $1 \mathrm{~h}$, before the last $3 \times 5$ min washes in TBS-T. Membranes were exposed to Chemiluminescent HRP Substrate (Millipore Corporation, Billerica, MA-US) for 5 min and bands quantified by Chemidoc XRS (BioRad, Hertfordshire, UK). Software measures were taken to prevent pixel saturation and protein loading were corrected to Coomassie staining.

\section{Statistics analysis}

Shapiro-Wilk test was used to check the normality assumption and skewed data were log transformed. In vitro data was analysed using a paired samples t-tests with the alpha level of significance set at $\mathrm{p}<0.05$. One-way analysis of variance (ANOVA) was used to assess differences between elderly with low (SMI below $28 \%$ ) and normal (SMI over 28\%) muscle mass. Linear regression was used to examine association between CRP z-score and SMI z-score with adjustments for BMI and age.

\section{Results}

The characteristics of older women included in this study are presented in Table 1. Elderly with low muscle mass (SMI<28\%) had significantly higher weight, BMI and triglycerides and lower leg strength compared to women with normal muscle mass (SMI>28\%) (table 1). Importantly, serum CRP was significantly higher in elderly with low muscle mass compared to those with
Table 1. Anthropometrics and clinical characteristics in all women and in groups with normal (SMI over 28\%) and low muscle mass (SMI below $28 \%$ ). Data is shown as mean $\pm \mathrm{SD} * \mathrm{p}<0.05$ Low vs Normal

\begin{tabular}{lccc}
\hline Muscle mass & All (n=118) & Normal (n=90) & Low (n=28) \\
Age (yrs) & $67 \pm 2$ & $68 \pm 2$ & $67 \pm 1$ \\
Height (cm) & $164.8 \pm 5.6$ & $165.1 \pm 5.6$ & $163.9 \pm 5.7$ \\
Weight (Kg) & $70.2 \pm 11.6$ & $67.3 \pm 10.6$ & $79.6 \pm 9.4^{*}$ \\
BMI (kg/m²) & $25.8 \pm 4.1$ & $24.7 \pm 3.7$ & $29.6 \pm 3.0^{*}$ \\
SMI (\%) & $30.6 \pm 3.9$ & $32.1 \pm 3.2$ & $25.8 \pm 0.3^{*}$ \\
CRP (mg/L) & $1.5 \pm 1.4$ & $1.2 \pm 1.1$ & $2.3 \pm 2.0^{*}$ \\
Triglycerides (mmol/L) & $1.1 \pm 0.4$ & $1.0 \pm 0.4$ & $1.3 \pm 0.6^{*}$ \\
Cholesterol (mmol/L) & $6.1 \pm 1.0$ & $6.1 \pm 1.0$ & $6.0 \pm 1.1$ \\
HDL (mmol/L) & $1.6 \pm 0.3$ & $1.6 \pm 0.3$ & $1.5 \pm 0.4$ \\
LDL (mmol/L) & $3.3 \pm 0.8$ & $3.3 \pm 0.7$ & $3.4 \pm 1.0$ \\
Glucose (mmol/L) & $5.3 \pm 0.6$ & $5.2 \pm 0.6$ & $5.4 \pm 0.5$ \\
Leg strength (N/Kg) & $2.6 \pm 0.7$ & $2.7 \pm 0.6$ & $2.3 \pm 0.7^{*}$ \\
\hline
\end{tabular}


Fig. 1. (A) Relationship between serum CRP level and skeletal muscle mass in elderly women. (B) The size of human myotubes exposed to CRP for 72h. (B) Myotubes are stained with antibodies against troponin (green), myogenin (red) and the nuclear marker DAPI (blue). (C) Muscle protein fractional synthetic rate (FSR) in human myotubes exposed to CRP for $24 \mathrm{~h}$. * $\mathrm{p}<0.05$.

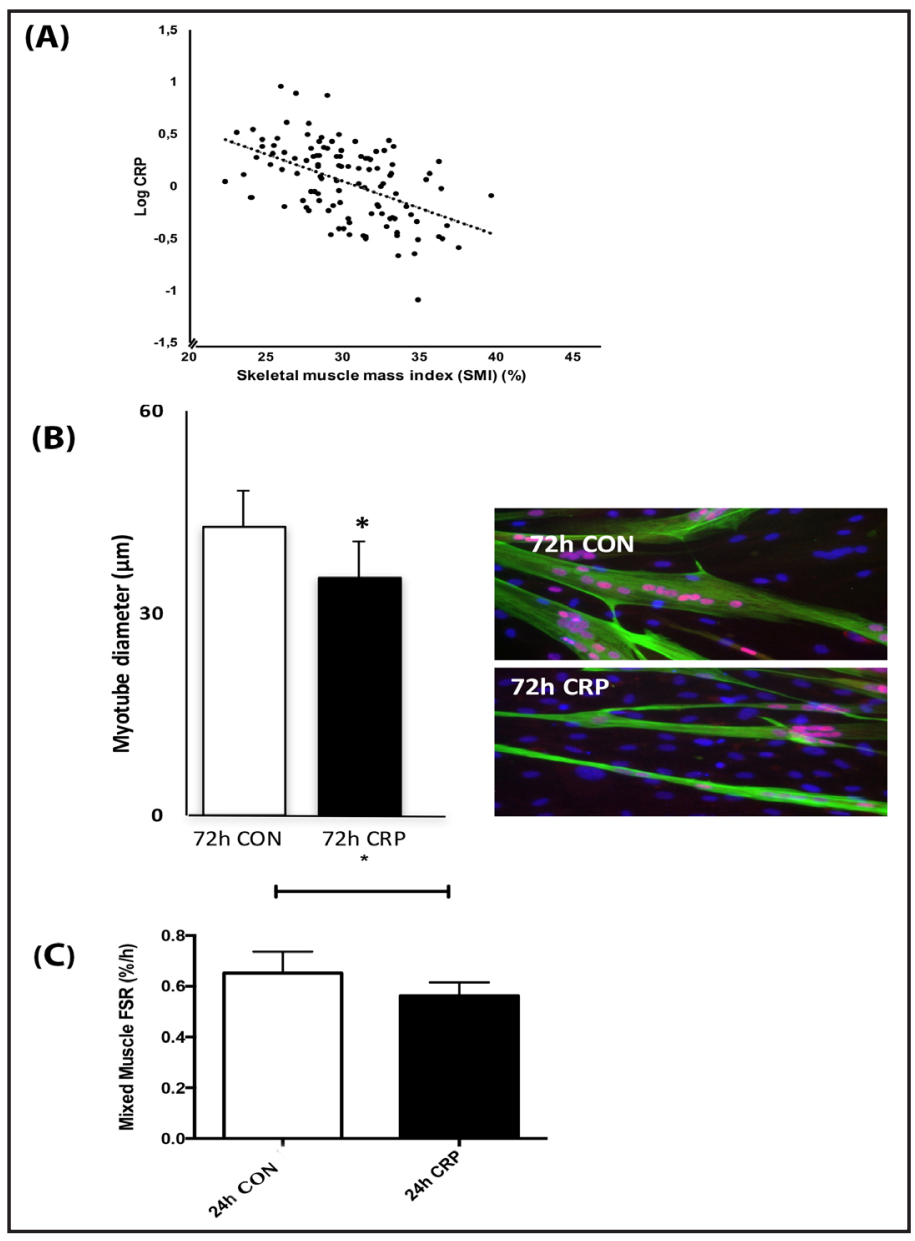

normal muscle mass and there was an inverse relationship between serum CRP and skeletal muscle mass $(\beta=-0.646(95 \% \mathrm{CI}:-0.888,-0.405) \mathrm{p}<0.05)$ (Fig. $1 \mathrm{~A})$. This relationship remained significant after adjustments for BMI $(\beta=-0.270$ (95\% CI: $-0.500,-0.041) \mathrm{p}<0.05)$ and BMI with age $(\beta=-0.254$ (95\% CI: $-0.482,-0.027) \mathrm{p}<0.05)$.

In vitro effects of CRP on myotube morphology, MPS and anabolic signalling

In order to address the mechanism underlying the relationship between muscle mass and serum CRP, we adopted an in-vitro model of exposing human muscle cells to CRP. Our first finding was that the size of human myotubes exposed to CRP for $72 \mathrm{~h}$ was significantly lower $(p<0.05)$ than that of control myotubes (Fig. 1B). Second, we hypothesized that the CRP-induced reduction of the size of muscle cells is partly mediated through a reduction in muscle protein synthesis. Muscle protein fractional synthetic rate (FSR) of human myotubes exposed to CRP for $24 \mathrm{~h}$ was measured using the stable isotope tracer deuterium oxide $\left(D_{2} 0\right)$. The coefficient of variation of FSR measurements was less than $3 \%$ when samples were measured repeatedly. Our findings revealed that muscle protein FSR was significantly lower $(\mathrm{p}<0.05)$ in CRP-treated myotubes compared to control myotubes (Fig. 1C). In order to address signalling pathways responsible for reduced muscle cell size and protein synthesis, myotubes were exposed to CRP for $12 \mathrm{~h}$ and $24 \mathrm{~h}$. There was a significant decrease $(p<0.05)$ in the phosphorylation of the serine/threonine kinase pAkt $^{\text {Ser473 }}$, which is an upstream regulator of the mechanistic target of rapamycin complex 1 (mTORc1), after $12 \mathrm{~h}$ CRP treatment (Fig. 2A). Moreover, a significant reduction $(\mathrm{p}<0.05)$ in phosphorylated ribosomal protein S6 (rpS6), a critical component of the $40 \mathrm{~S}$ ribosomal subunit, occurred after 12h CRP treatment (Fig. 2B). We further sought to determine whether a CRP-mediated increased phosphorylation of the sensor of cellular energy stress AMP-activated protein 
Fig. 2. Phosphorylated Akt (A) and ribosomal protein S6 (rpS6) (B) in human myotubes exposed to CRP for $12 \mathrm{~h}$ and 24 h. Data are means (bars represent SEM). $* \mathrm{p}<0.05$.
Fig. 3. Phosphorylated AMP-activated protein kinase (AMPK) (A) and raptor (B) in human myotubes exposed to CRP for $12 \mathrm{~h}$ and 24 h. Data are means (bars represent SEM). ${ }^{*} \mathrm{p}<0.05 .{ }^{* *} \mathrm{p}<0.01$.
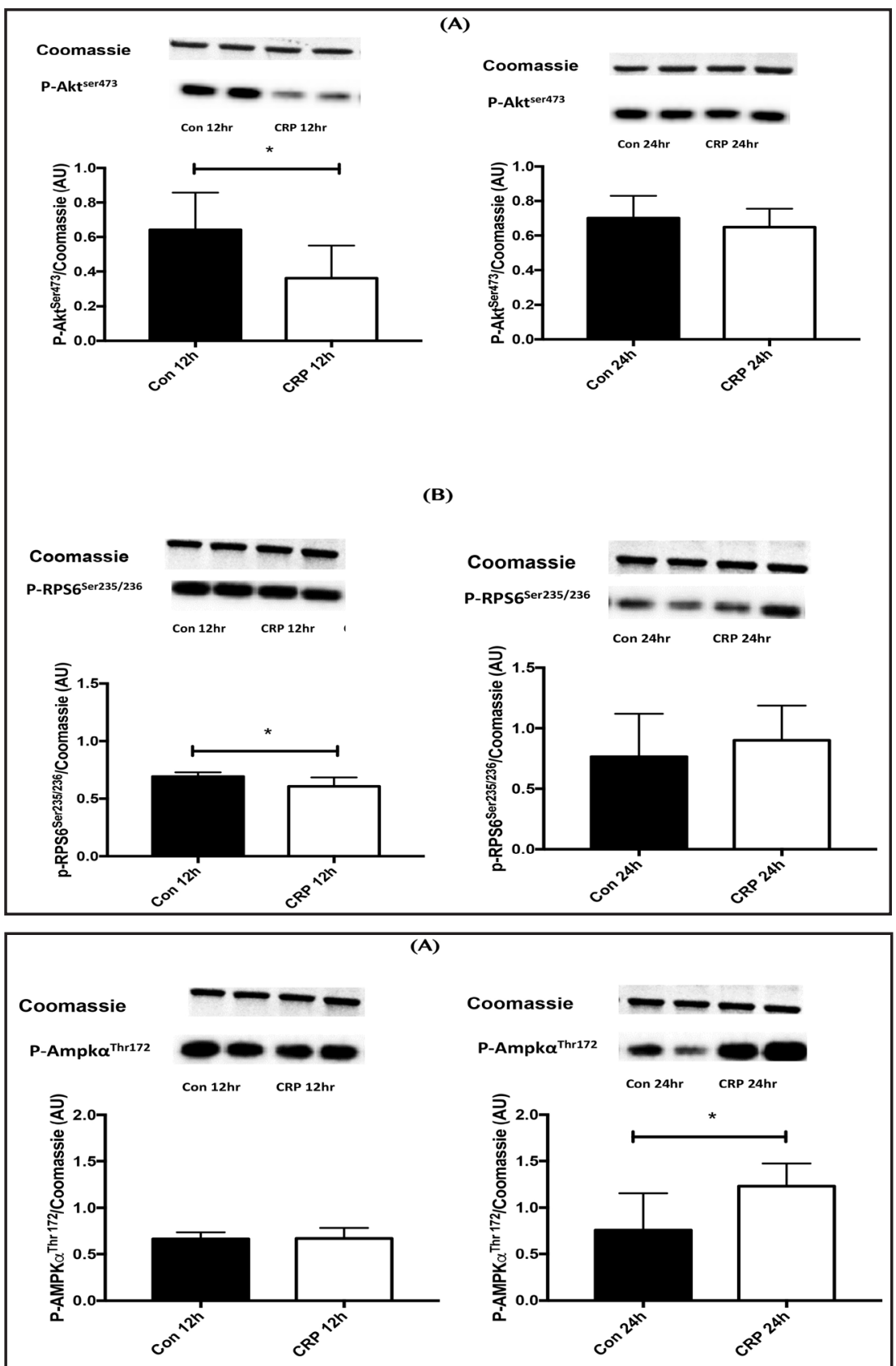

(B)

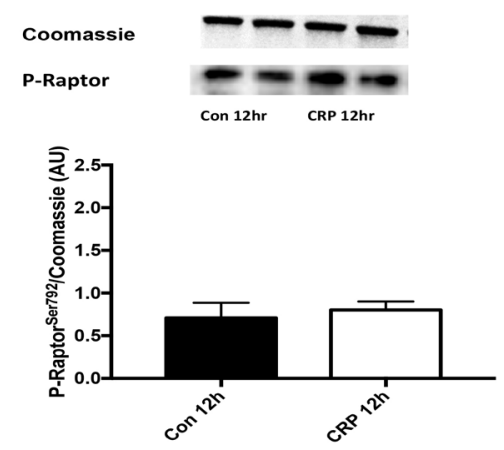




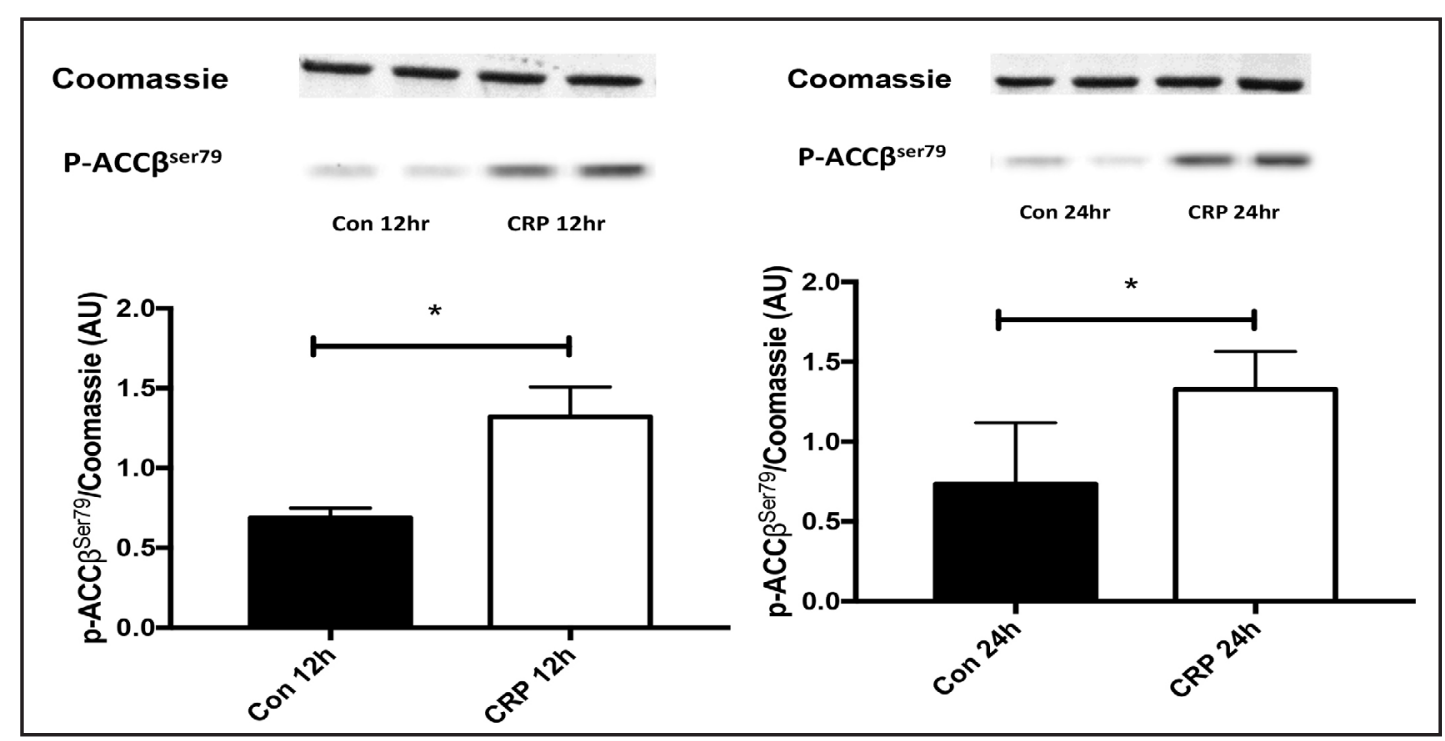

Fig. 4. Phosphorylated acetyl-CoA carboxylase (ACC- $\beta$ ) in human myotubes exposed to CRP for $12 \mathrm{~h}$ and 24 h. Data are means (bars represent SEM). * $\mathrm{p}<0.05$.

kinase (AMPK) may underlie reduced cell growth. There was evidence that CRP contributes to the onset of cellular energy stress with significant increase in phosphorylation of AMPK at $24 \mathrm{~h}(\mathrm{p}<0.05)(\mathrm{Fig} .3 \mathrm{~A})$. Significant increase in phosphorylation of the AMPK target and mTOR binding partner, raptor occurred after $24 \mathrm{~h}$ incubation in CRP $(\mathrm{p}<0.05)$, which further contributes to the inhibition of the mTORc1 (Fig. 3B). We also report the upregulation of another target of AMPK, acetyl-CoA carboxylase $($ ACC $-\beta)$ at $12 \mathrm{~h}(\mathrm{p}<0.05)$ and $24 \mathrm{~h}(\mathrm{p}<0.05)$ (Fig. 4).

\section{Discussion}

Previous epidemiological reports have set the basis for the extensive interest on the impact of circulating CRP upon the deterioration of muscle mass and function [9-14]. The present study confirmed that elevated circulating serum CRP levels in community-dwelling elderly women are negatively associated with muscle mass; Importantly, we have shown that CRP influences muscle cell size and identified for the first time a mechanistic link by which CRP mediates its effects on skeletal muscle via suppression of MPS pathway.

The occurrence of an inverse relationship between circulating serum CRP and muscle mass suggests that the level of chronic systemic inflammation (or actually CRP per se) is an important factor involved in control of muscle mass in elderly. This is supported by others who also reported robust associations between CRP and physical decline [26, 27]. Our data are in accordance with those indicating that elderly with elevated circulating inflammatory markers experienced the greatest loss of thigh muscle area over a 5 y period [28] and that higher circulating CRP levels are related to lower muscle strength in older adults $[11,12]$. Lower muscle strength and higher circulating CRP levels in elderly with low muscle mass is of clinical relevance as force-generating capacity is an important factor limiting the ability of the elderly to perform basic activities of daily living [29] and knee extensor strength is considered as an important factor limiting the ability to rise from a chair [30]. Of note, although our data support conclusions from previous epidemiological studies, a limitation to the present study is the use of bioimpedance (BIA) analysis for the assessment of skeletal muscle mass. Noteworthy, despite the highest accuracy of computed tomography and magnetic resonance imaging, sarcopenia diagnosis is based on BIA or dual x-ray absorptiometry (DXA) measurements. In standardized conditions (body position, 


\section{Cellular Physiology Cell Physiol Biochem 2017;44:267-278 and BiOChemistry Published online: November 09, 2017 \begin{tabular}{l|l} 
DOI: $10.1159 / 000484679$ & $\begin{array}{l}\text { C } 2017 \text { The Author(s). Published by S. Karger AG, Basel } \\
\text { www.karger.com/cpb }\end{array}$
\end{tabular}

previous exercise, hydration status and dietary intake) and using an equation previously cross-validated against MRI [31], BIA method is currently considered as an accurate measurement of functioning muscle mass in clinical settings and epidemiological studies. The advantages of BIA (no exposure to radiation, ease to use, relatively low cost and safety) make it appropriate for large-scale studies. Moreover, BIA or DXA-based cut-off points are currently used for the definition of sarcopenia in accordance with recommendations from the European Working Group on Sarcopenia in Older People (EWGSOP). Another limitation inherent to data on associations between CRP and muscle characteristics in this and in similar studies is the cross-sectional design. The possibility that the observational associations may be attributable to confounding and/or reverse causality cannot be excluded. Previous studies on observational links between systemic inflammation and sarcopenia reported significant associations even after adjustments with sex, level of education, smoking history, alcohol use, physical exercise and history of chronic diseases $[11,14]$. In our study, all subjects were non-smoking women with no disability regarding mobility and free of metabolic and inflammatory diseases, diagnosed coronary heart disease or diabetes mellitus, which reduces the number of confounding factors. Importantly, our invitro data provide a mechanistic model supporting epidemiological links between chronic inflammation and muscle mass and suggesting a direct action of CRP on the size of muscle cells, a major physiological endpoint. However, a future major challenge is to identify stimuli leading to chronic elevations in systemic inflammation.

The progressive loss of muscle mass during ageing due to both a reduction in muscle fibre number and area [32] may be attributed to intrinsic properties of the cell itself or to the influence of its environment. Numerous experiments have highlighted a potential role for "systemic" drivers. For instance, a reduction in the proliferative rate of myogenic cells was evident in cells exposed to sera from elderly women with elevated CRP levels [19]. Interestingly, elevated CRP levels in sera from elderly can affect the proliferative rate of other cells including endothelial cells [33]. It has also been shown that the exposure of myogenic cells to sera from young can rejuvenate cell proliferative capacity [34-36]. Thus, testable hypothesis is that relationship between serum CRP and muscle mass could perhaps be explained by a CRP-mediated reduction of the size of the muscle cells.

To our knowledge ours is the first report combining assessment of the influence of CRP on muscle mass and muscle cell size together with the in-vitro monitoring of MPS. We have identified a CRP-mediated reduction of the size of human myotubes (a major physiological endpoint) together with reduction of MPS as a mechanism underlying the negative effects of CRP on muscle mass. Given that myofibrillar proteins represent $\sim 85 \%$ of muscle fibre volume [37] any factor able to influence the balance of myofibrillar protein metabolism may contribute to muscle atrophy. In this respect, as the stimulation of mTORc1 is instrumental to the control of MPS [38], the phosphorylation state of several constituents interacting with the growth mTORC1-pathway were investigated. Our findings revealed a CRP-mediated reduction in phosphorylation of Akt, the major upstream regulator of mTOR cascade involved in the regulation of muscle growth [38]. Reduced activity in this key upstream factor may provide an explanation for the impairment of MPS in muscle cells exposed to CRP. Additionally, while cellular energetics per se were not the focus of this work, the CRP-mediated downregulation of Akt could also theoretically be linked to impaired muscle glucose disposal [39]. In addition to the influence of CRP on Akt, the observed reduction in phosphorylated ribosomal protein S6 (rpS6), a critical component of the $40 \mathrm{~S}$ ribosomal subunit may further contribute to impaired MPS. In parallel with downregulation of factors involved in MPS, our data also indicate an upregulation of AMPK, suggesting that CRP may involve an induction of cellular energy stress [40]. It has previously been shown that under conditions of cellular energy stress, increased phosphorylation of the AMPK leads to the suppression of mTORC1 activity [41-43]. Our study also reveals an upregulation of the two AMPK downstream targets, raptor and ACC- $\beta$. In particular, CRP-mediated increased phosphorylation of raptor, a direct substrate of AMPK and an mTOR-binding-partner is inextricably linked to the inhibition of the mTORC1 [42]. Noteworthy, decreased phosphorylation of rpS6 occurred 


\section{Cellular Physiology Cell Physiol Biochem 2017;44:267-278 and BiOChemistry Published online: November 09, 2017 \begin{tabular}{l|l} 
DOI:10.1159/000484679 & $\begin{array}{l}\text { C } 2017 \text { The Author(s). Published by S. Karger AG, Basel } \\
\text { www.karger.com/cpb }\end{array}$
\end{tabular}

before the occurrence of significant increases in AMPK phosphorylation suggesting an AMPindependent regulation of rpS6. Future time-course and pharmacological work are needed to determine the mechanistic role of AMPK in CRP-induced cellular catabolism. Altogether, although several other signalling molecules may act on muscle growth [44] and mediate the effects of systemic inflammation on skeletal muscle, our data revealed potentially important mechanisms by which CRP might exert its effect on muscle mass; especially given the major role played by the Akt/mTOR and AMPK signalling pathways in the control of MPS $[45,46]$. Nevertheless, it is important to emphasize the limitation inherent to the study of underlying molecular pathways responsible for altered protein synthesis on the basis on snapshot measures of phosphorylation which are captured at specific windows of a dynamic process. Furthermore, elevations of systemic markers of inflammation during ageing are small, progressive and chronic, a process which is difficult to model in-vitro. In this respect, a limitation to this work is the use of a single in-vitro concentration to depict the influence of CRP on muscle cell function. However, dose response studies $(0-100 \mu \mathrm{g} / \mathrm{ml}$ CRP) investigating the effects of CRP on cell function showed that the amplitude of the physiological response increased with increasing CRP concentration with a maximal response at $50 \mu \mathrm{g} /$ $\mathrm{ml}$, a concentration which has been used in several previous studies depicting the influence of CRP on other cell types including endothelial cells and smooth muscle cells [47-49]. Our work, established the impact of CRP on a critical physiological endpoint (muscle cell size) using a concentration commonly used to describe the in-vitro effects of CRP on cell function. Noteworthy, tissues and cells in elderly are exposed to lower circulating CRP concentrations during several years and effects of CRP might be potentiated by the presence of other proinflammatory inflammatory mediators including fibrinogen, TNF- $\alpha$, IL-1 $\beta$ and IL-6.

The age-related occurrence of an anabolic resistance has been linked to the progression of sarcopenia $[3,21,50]$. The basis for the reduction of MPS during sarcopenia is likely to be multifactorial and factors able to exert a biologically significant effect may include an insulin/insulin-like growth factor-1 (IGF-1) resistance, increased pro-inflammatory cytokines, malnutrition, corticosteroids, and/or reduced physical activity [51]. Our findings support the hypothesis that increased CRP levels during aging could contribute to anabolic resistance (although we did not test the premise directly). Moreover, observational findings about the influence of the systemic environment on MPS have been previously addressed; albeit yielding conflicting results. Data from the one group indicated that while circulating CRP levels were associated with reduced MPS in older rats, protein metabolism was not associated with CRP levels in elderly humans [22]. In contrast, lower muscle MPS has been reported in elderly compared to young and an inverse relationship was found between the level of circulating serum CRP and MPS [20]. As highlighted by Buffière et al. (2015) [22] between-study differences in health and systemic inflammatory status might explain the conflicting results. Indeed, data on the relationship between the in-vivo monitoring of MPS in humans and circulating inflammatory markers at any given time point pose considerable problems of interpretation. For example, the in-vivo monitoring of human MPS is unlikely to be under the sole influence of CRP as other circulating factors such as IL- 6 or TNF- $\alpha$ alpha might act in concert with CRP to potentiate its effects on muscle protein synthesis whereas others factors such as IGF-1 might oppose the effects of CRP. Nonetheless, our in-vitro monitoring of MPS in human muscle cells exposed to CRP allowed us to identify a direct and potentially mechanistic link between CRP and atrophic phenotype.

\section{Conclusion}

Our work has established both observational and mechanistic links by which chronic elevation of the inflammatory marker CRP could mediate age-related declines in muscle mass. Identification of links between declines in muscle mass and chronic inflammation could prove instrumental for development of therapeutic interventions to prevent and treat sarcopenia. 


\section{Cellular Physiology Cell Physiol Biochem 2017;44:267-278

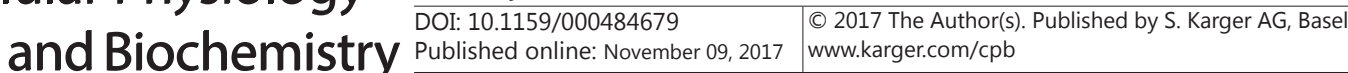

Wåhlin-Larsson et al.: CRP, Protein Synthesis \& Muscle Mass in Elderly

\section{Acknowledgements}

This work was supported by grants from the Swedish National Center for Research in Sports (P2012/0102 and P2014-0117).

\section{Disclosure Statement}

Authors declare no Disclosure Statement.

\section{References}

1 Metter EJ, Talbot LA, Schrager M, Conwit R: Skeletal muscle strength as a predictor of all-cause mortality in healthy men. J Gerontol A Biol Sci Med Sci 2002;57:359-365.

- Janssen I, Heymsfield SB, Ross R: Low relative skeletal muscle mass (sarcopenia) in older persons is associated with functional impairment and physical disability. J Am Geriatr Soc 2002;50:889-896.

3 Cuthbertson D, Smith K, Babraj J, Leese G, Waddell T, Atherton P, Wackerhage H, Taylor PM, Rennie MJ: Anabolic signaling deficits underlie amino acid resistance of wasting, aging muscle. FASEB J 2005;19:422424.

4 Greig CA, Gray C, Rankin D, Young A, Mann V, Noble B, Atherton PJ: Blunting of adaptive responses to resistance exercise training in women over 75y. Exp Gerontol 2011;46:884-890.

5 Koopman R, Walrand S, Beelen M, Gijsen AP, Kies AK, Boirie Y, Saris WH, van Loon LJ: Dietary protein digestion and absorption rates and the subsequent postprandial muscle protein synthetic response do not differ between young and elderly men. J Nutr 2009;139:1707-1713.

6 Moore DR, Churchward-Venne TA, Witard O, Breen L, Burd NA, Tipton KD, Phillips SM: Protein ingestion to stimulate myofibrillar protein synthesis requires greater relative protein intakes in healthy older versus younger men. J Gerontol A Biol Sci Med Sci 2015;70:57-62.

7 Drummond MJ, Fry CS, Glynn EL, Dreyer HC, Dhanani S, Timmerman KL, Volpi E, Rasmussen BB: Rapamycin administration in humans blocks the contraction-induced increase in skeletal muscle protein synthesis. J Physiol 2009;587:1535-1546.

8 Rieu I, Magne H, Savary-Auzeloux I, Averous J, Bos C, Peyron MA, Combaret L, Dardevet D: Reduction of low grade inflammation restores blunting of postprandial muscle anabolism and limits sarcopenia in old rats. J Physiol 2009;587:5483-5492.

-9 Visser M, Pahor M, Taaffe DR, Goodpaster BH, Simonsick EM, Newman AB, Nevitt M, Harris TB: Relationship of interleukin- 6 and tumor necrosis factor-alpha with muscle mass and muscle strength in elderly men and women: the Health ABC Study. J Gerontol A Biol Sci Med Sci 2002;57:326-332.

10 Cesari M, Kritchevsky SB, Baumgartner RN, Atkinson HH, Penninx BW, Lenchik L, Palla SL, Ambrosius WT, Tracy RP, Pahor M: Sarcopenia, obesity, and inflammation--results from the Trial of Angiotensin Converting Enzyme Inhibition and Novel Cardiovascular Risk Factors study. Am J Clin Nutr 2005;82:428-434.

-11 Schaap LA, Pluijm SM, Deeg DJ, Visser M: Inflammatory markers and loss of muscle mass (sarcopenia) and strength. Am J Med 2006;119:526.

12 Hamer M, Molloy GJ: Association of C-reactive protein and muscle strength in the English Longitudinal Study of Ageing. Age (Dordr) 2009;31:171-177.

13 Kim TN, Park MS, Lim KI, Choi HY, Yang SJ, Yoo HJ, Kang HJ, Song W, Choi H, Baik SH, Choi DS, Choi KM: Relationships between sarcopenic obesity and insulin resistance, inflammation, and vitamin D status: the Korean Sarcopenic Obesity Study. Clin Endocrinol (Oxf) 2013;78:525-532.

14 Yang CW, Li CI, Li TC, Liu CS, Lin CH, Lin WY, Lin CC: Association of Sarcopenic Obesity with Higher Serum High-Sensitivity C-Reactive Protein Levels in Chinese Older Males-A Community-Based Study (Taichung Community Health Study-Elderly, TCHS-E). PLoS One 2015;10:e0132908.

15 Blake GJ, Ridker PM: Inflammatory bio-markers and cardiovascular risk prediction. J Intern Med 2002;252:283-294.

-16 Ferrucci L, Corsi A, Lauretani F, Bandinelli S, Bartali B, Taub DD, Guralnik JM, Longo DL: The origins of agerelated proinflammatory state. Blood 2005;105:2294-2299. 


\section{Cellular Physiology Cell Physiol Biochem 2017;44:267-278

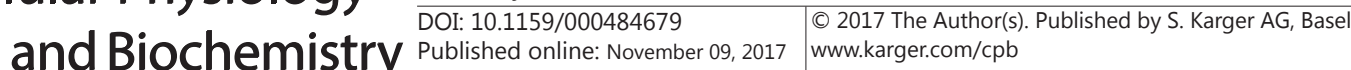 \\ Wåhlin-Larsson et al.: CRP, Protein Synthesis \& Muscle Mass in Elderly}

17 Eklund CM: Proinflammatory cytokines in CRP baseline regulation. Adv Clin Chem 2009;48:111-136.

18 Ansar W, Ghosh S: C-reactive protein and the biology of disease. Immunol Res 2013;56:131-142.

19 Wahlin-Larsson B, Carnac G, Kadi F: The influence of systemic inflammation on skeletal muscle in physically active elderly women. Age (Dordr) 2014;36:9718.

20 Toth MJ, Matthews DE, Tracy RP, Previs MJ: Age-related differences in skeletal muscle protein synthesis: relation to markers of immune activation. Am J Physiol Endocrinol Metab 2005;288:E883-91.

21 Balage M, Averous J, Remond D, Bos C, Pujos-Guillot E, Papet I, Mosoni L, Combaret L, Dardevet D: Presence of low-grade inflammation impaired postprandial stimulation of muscle protein synthesis in old rats. J Nutr Biochem 2010;21:325-331.

-22 Buffiere C, Mariotti F, Savary-Auzeloux I, Migne C, Meunier N, Hercberg S, Cano N, Remond D, Duclos M, Dardevet D: Slight chronic elevation of C-reactive protein is associated with lower aerobic fitness but does not impair meal-induced stimulation of muscle protein metabolism in healthy old men. J Physiol 2015;593:1259-1272.

23 Strandberg E, Edholm P, Ponsot E, Wahlin-Larsson B, Hellmen E, Nilsson A, Engfeldt P, Cederholm T, Riserus U, Kadi F: Influence of combined resistance training and healthy diet on muscle mass in healthy elderly women: a randomized controlled trial. J Appl Physiol (1985) 2015;119:918-925.

24 Yang D, Diraison F, Beylot M, Brunengraber DZ, Samols MA, Anderson VE, Brunengraber H: Assay of low deuterium enrichment of water by isotopic exchange with [U-13C3]acetone and gas chromatography-mass spectrometry. Anal Biochem 1998;258:315-321.

25 Gasier HG, Fluckey JD, Previs SF: The application of 2H20 to measure skeletal muscle protein synthesis. Nutr Metab (Lond) 2010;7:31.

-26 Cesari M, Penninx BW, Pahor M, Lauretani F, Corsi AM, Rhys Williams G, Guralnik JM, Ferrucci L: Inflammatory markers and physical performance in older persons: the InCHIANTI study. J Gerontol A Biol Sci Med Sci 2004;59:242-248.

-27 Sousa AC, Zunzunegui MV, Li A, Phillips SP, Guralnik JM, Guerra RO: Association between C-reactive protein and physical performance in older populations: results from the International Mobility in Aging Study (IMIAS). Age Ageing 2016;45:274-280.

-28 Schaap LA, Pluijm SM, Deeg DJ, Harris TB, Kritchevsky SB, Newman AB, Colbert LH, Pahor M, Rubin SM, Tylavsky FA, Visser M: Higher inflammatory marker levels in older persons: associations with 5-year change in muscle mass and muscle strength. J Gerontol A Biol Sci Med Sci 2009;64:1183-1189.

29 Wolfson L, Judge J, Whipple R, King M: Strength is a major factor in balance, gait, and the occurrence of falls. J Gerontol A Biol Sci Med Sci 1995;50:64-67.

-30 Hughes MA, Myers BS, Schenkman ML: The role of strength in rising from a chair in the functionally impaired elderly. J Biomech 1996;29:1509-1513.

-31 Janssen I, Heymsfield SB, Baumgartner RN, Ross R: Estimation of skeletal muscle mass by bioelectrical impedance analysis. J Appl Physiol (1985) 2000;89:465-471.

-32 Lexell J: Human aging, muscle mass, and fiber type composition. J Gerontol A Biol Sci Med Sci 1995;50:1116.

-33 Hosford-Donovan A, Nilsson A, Wahlin-Larsson B, Kadi F: Observational and mechanistic links between C-reactive protein and blood pressure in elderly women. Maturitas 2016;89:52-57.

34 Conboy IM, Conboy MJ, Wagers AJ, Girma ER, Weissman IL, Rando TA: Rejuvenation of aged progenitor cells by exposure to a young systemic environment. Nature 2005;433:760-764.

-35 Carlson ME, Suetta C, Conboy MJ, Aagaard P, Mackey A, Kjaer M, Conboy I: Molecular aging and rejuvenation of human muscle stem cells. EMBO Mol Med 2009;1:381-391.

-36 Barberi L, Scicchitano BM, De Rossi M, Bigot A, Duguez S, Wielgosik A, Stewart C, McPhee J, Conte M, Narici M, Franceschi C, Mouly V, Butler-Browne G, Musarò A: Age-dependent alteration in muscle regeneration: the critical role of tissue niche. Biogerontology 2013;14:273-292.

37 Hoppeler H: Exercise-induced ultrastructural changes in skeletal muscle. Int J Sports Med 1986;7:187-204.

-38 Favier FB, Benoit H, Freyssenet D: Cellular and molecular events controlling skeletal muscle mass in response to altered use. Pflugers Arch 2008;456:587-600.

-39 Ward PS, Thompson CB: Signaling in control of cell growth and metabolism. Cold Spring Harb Perspect Biol 2012;4:a006783.

40 Hardie DG, Sakamoto K: AMPK: a key sensor of fuel and energy status in skeletal muscle. Physiology (Bethesda) 2006;21:48-60. 


\section{Cellular Physiology Cell Physiol Biochem 2017;44:267-278

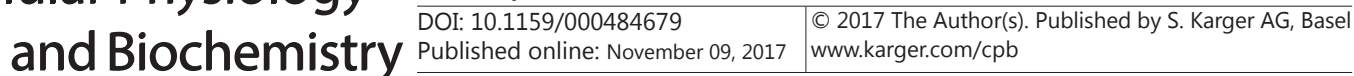 \\ Wåhlin-Larsson et al.: CRP, Protein Synthesis \& Muscle Mass in Elderly}

41 Bolster DR, Crozier SJ, Kimball SR, Jefferson LS: AMP-activated protein kinase suppresses protein synthesis in rat skeletal muscle through down-regulated mammalian target of rapamycin (mTOR) signaling. J Biol Chem 2002;277:23977-23980.

-42 Gwinn DM, Shackelford DB, Egan DF, Mihaylova MM, Mery A, Vasquez DS, Turk BE, Shaw RJ: AMPK phosphorylation of raptor mediates a metabolic checkpoint. Mol Cell 2008;30:214-226.

-43 Deng M, Yang X, Qin B, Liu T, Zhang H, Guo W, Lee SB, Kim JJ, Yuan J, Pei H, Wang L, Lou Z: Deubiquitination and Activation of AMPK by USP10 Mol Cell 2016;61:614-624.

44 Schiaffino S, Dyar KA, Ciciliot S, Blaauw B, Sandri M: Mechanisms regulating skeletal muscle growth and atrophy. FEBS J 2013;280:4294-4314.

45 Crossland H, Kazi AA, Lang CH, Timmons JA, Pierre P, Wilkinson DJ, Smith K, Szewczyk NJ, Atherton PJ: Focal adhesion kinase is required for IGF-I-mediated growth of skeletal muscle cells via a TSC2/mTOR/ S6K1-associated pathway. Am J Physiol Endocrinol Metab 2013;305:E183-193.

46 Brook MS, Wilkinson DJ, Mitchell WK, Lund JN, Szewczyk NJ, Greenhaff PL, Smith K, Atherton PJ: Skeletal muscle hypertrophy adaptations predominate in the early stages of resistance exercise training, matching deuterium oxide-derived measures of muscle protein synthesis and mechanistic target of rapamycin complex 1 signaling. FASEB J 2015;29:4485-4496.

47 Pasceri V, Willerson JT, Yeh ET: Direct proinflammatory effect of C-reactive protein on human endothelial cells. Circulation 2000;102:2165-2168.

48 Devaraj S, Yun JM, Duncan-Staley C, Jialal I: C-reactive protein induces M-CSF release and macrophage proliferation. J Leukoc Biol 2009;85:262-267.

49 Aas V, Sand KL, Asheim HC, Benestad HB, Iversen JG: C-reactive protein triggers calcium signalling in human neutrophilic granulocytes via FcgammaRIIa in an allele-specific way. Scand J Immunol 2013;77:442-451.

-50 Guillet C, Prod'homme M, Balage M, Gachon P, Giraudet C, Morin L, Grizard J, Boirie Y: Impaired anabolic response of muscle protein synthesis is associated with S6K1 dysregulation in elderly humans. FASEB J 2004;18:1586-1587.

51 Gordon BS, Kelleher AR, Kimball SR: Regulation of muscle protein synthesis and the effects of catabolic states. Int J Biochem Cell Biol 2013;45:2147-2157. 